\section{Thickness of lithosphere deduced from gravity edge effects across the Mendocino Fault}

- THE evolution of a lithospheric plate, as it migrates away from the accreting boundary (mid-ocean ridge crest), is mostly a result of vertical cooling by conduction. As density is a function of temperature and pressure, the density structure should be a function of the age of the plate and, in order to preserve isostatic equilibrium, the seafloor should subside as the plate cools ${ }^{1}$. Thus. the variation of heat flow, seafloor depth and the gravity field are different expressions of the same process, progressive cooling, occurring over the whole thickness of the plate. Sclater and Francheteau ${ }^{2}$ have verified these properties through an analysis of the variation of heat flow and depth with the age of the plate. Their model assumed that the plate remains a constant thickness and is floating in hydrostatic equilibrium over the asthenosphere. This led to an estimate of $75 \mathrm{~km}$ for the thickness of the plate. -

Unfortunately, analysis of variation of the gravity field gives little information about structures in isostatic equilibrium with small lateral variations. Beyond the fact that the underlying volumes are of equal weight, the only information it gives comes from the influence of the lateral variation of density structure on the surface gravity field. As the evolution of the plate is slow, with a thermal constant of about 80 Myr (ref. 3), the lateral variations are small and difficult to detect, except perhaps near the accreting plate boundary4. Talwani et al. ${ }^{5}$ have shown, however, that over the Mid-Atlantic Ridge, gravity data combined with crustal seismic refraction data ${ }^{6}$ imply the existence of a low density upper mantle body of so-called 'anomalous mantle' at shallow depth (less than $40 \mathrm{~km}$ ) below the surface. Their conclusion is in qualitative agreement with the low densities predicted by the plate tectonics model. But Morgan? has argued that gravity data alone cannot rule out the existence of a much deeper compensating body. Keen and Tramontini ${ }^{8}$ have assumed that this compensation comes from a mass with a uniformly low density contrast, extending to depths of $200 \mathrm{~km}$.

This controversy could be settled ${ }^{3}$ with gravity data alone, by studying active or fossil transform fault areas with large offsets, which juxtapose lithospheric plates of different ages (Fig. 1). The resulting large gravity edge effects are quite sensitive to the depths of the compensating masses. We show here that the gravity edge effect produced by the fossil Mendocino Fault - a transform fault-can be explained with Sclater and Francheteau's plate model ${ }^{2}$, and that the most probable thickness of the plate is $75 \pm 25 \mathrm{~km}$.

Figure 1 shows the location of three gravity profiles ${ }^{9.10}$ across the Mendocino Fracture Zone. Magneticlineations data ${ }^{11}$ show that the lithosphere on each side of the fault differs in age by $30 \mathrm{Myr}$. Figure 2 shows the free-air gravity anomaly profiles and the corresponding density models proposed ${ }^{9.10}$ to explain them. The crustal density structure adopted ${ }^{9.10}$ for profiles $a$ and $b$ (Fig. 2) are based on nearby seismic refraction measurements ${ }^{12}$ using the Nafe and Drake velocity/density relationship ${ }^{13}$. There is no seismic refraction station near profile $c$ (Fig. 1) but Dehlinger et al ${ }^{9.10}$ projected results from refraction stations hundreds of kilometres away. In addition, they did not allow for the velocity anisotropy at the Moho interface ${ }^{14-16}$. The density structure they obtained for the mantle is, consequently, rather heterogeneous. In spite of these limitations, their results show the existence, on profiles $a$ and $b$ (Fig. 1), of an edge effect with a $70 \mathrm{mgal}$ low about $100 \mathrm{~km}$ wide south of Mendocino. They explain this by invoking a compensating mass which is about $0.2 \mathrm{~g} \mathrm{~cm}^{-3}$ lighter in the upper part of the mantle, as originally proposed by Talwani et $a l^{5}$. The edge effect decreases in amplitude but increases in width on profile $c$ (Fig. 1), as predicted by the plate tectonics hypothesis of thermal evolution of the lithosphere.

We concentrate on profiles $a$ and $b$ (Fig. 1) which have a better crustal seismic refraction control and in which the contrast in thermal structure should be greatest, according to the plate tectonics model. The crustal density structure adopted was given by Dehlinger et al. ${ }^{9.10}$. The density structure of the mantle is deduced from the vertical temperature distribution computed using Sclater and Francheteau's model ${ }^{2}$ for a lithospheric plate of corresponding age. We also use their constants. The temperature of the asthenosphere is taken as $1,300^{\circ} \mathrm{C}$ and the density of mantle material at $0^{\circ} \mathrm{C}$ as $3.4 \mathrm{~g} \mathrm{~cm}^{-3}$. The only variable parameter is the thickness of the lithosphere, which we choose to vary between 25 and $200 \mathrm{~km}$.

In practice, the density distribution within the lithosphere is computed by assuming that the ocean floor is the top of the lithosphere, but for the part of the lithosphere corresponding to the crust we adopt the density distribution deduced from seismic refraction results. We divide the remaining part of the lithosphere into layers of constant density differing by $0.01 \mathrm{~g}$ $\mathrm{cm}^{-3}$; the mean density of the layer is obtained from the Sclater and Francheteau model ${ }^{2}$. Corresponding columns on each side of the fracture zone do not have exactly the same weight. because the temperature has been computed for a constant volume lithosphere and because the crust is ignored in the temperature-density model. We restore hydrostatic equilibrium between the two columns by applying to the older a small thickness correction which is proportional to the difference between the mean computed density of a given layer and the density of the asthenosphere. We also ignore the modification of temperature structure which occurs because of heat flowing by conduction across the fossil transform fault. It can be shown that both simplifications introduce only second order modifica-
Fig. 1 Bathymetric map, after Chase et al. ${ }^{18}$, showing gravity profiles $a, b$, and $c$ (see text). profiles $a, b$, and $c$ (see text).
Heavy lines, magnetic lineations with ages given in Myr (after Atwater and Menard ${ }^{11}$ ). The Mendocino Fracture Zone juxtaposes sections of lithosphere which are of different ages: across profile $a, 0.3$ and $31 \mathrm{Myr}$ : $b, 3$ and $33 \mathrm{Myr} ; c, 11$ and 40 Myr.

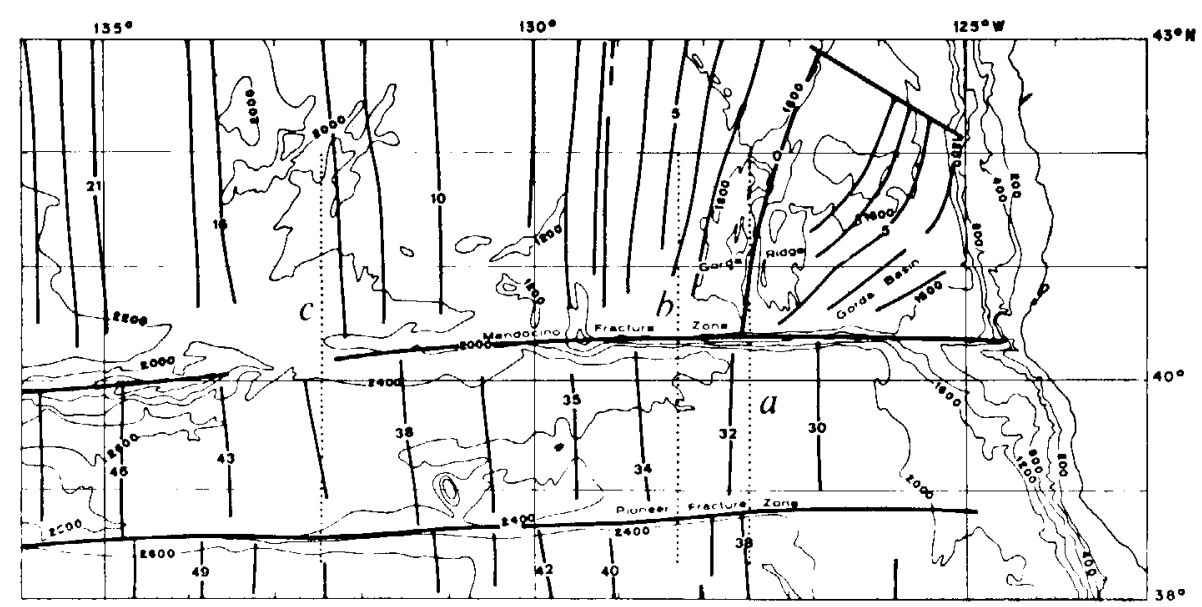


tions. We felt that the many uncertainties in the data did not warrant testing more elaborate models, such as that proposed by Parker and Oldenburg ${ }^{17}$. Figure 3 shows the density models for profiles $a$ and $b$.
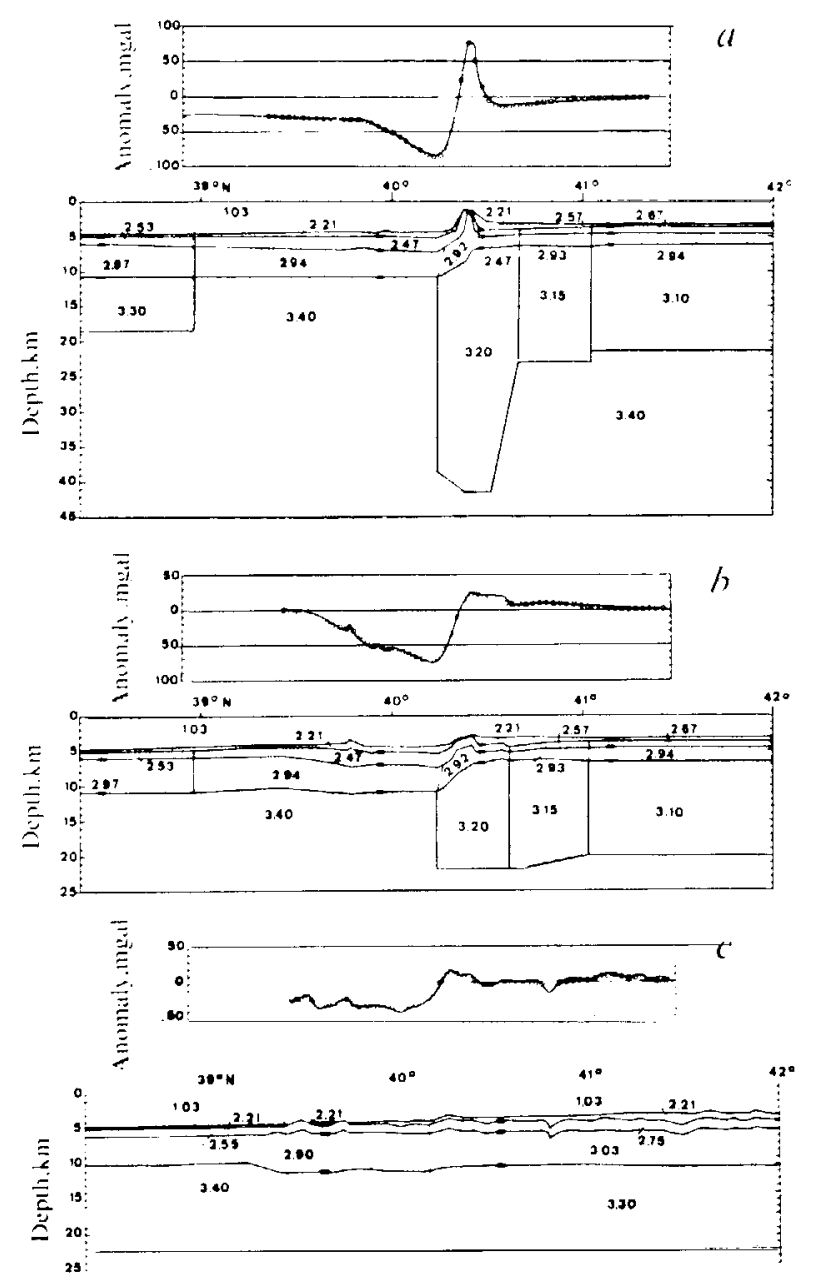

Fig. 2 Gravity profiles (free-air anomalies), and crustal sections along profiles $a$ (along $12720^{\prime} \mathrm{W}$ ), $b$ (along $128,20^{\prime} \mathrm{W}$ ) and $c$ (along $13230 \mathrm{~W}$. In crustal sections, depth is shown from sea level, and densities $\left(\mathrm{g} \mathrm{cm}^{-3}\right)$ are given. Data from refs 9 and 10 .

Figure 3 shows the difference between the observed anomaly and computed gravity anomaly for different models in which the only parameter changed is the thickness of the lithosphere. If the plate tectonics model is correct and if the thickness of lithosphere adopted corresponds to reality, the resulting difference would be zero everywhere. If the thickness is too large then the edge effect is too large and the difference should be positive south of Mendocino and negative north of it. Comparison between computed and observed gravity anomalies shows that the best fits are obtained for a thickness of $75 \mathrm{~km}$ (Figs 3 and 4). The data are not good enough to exclude definitely a thickness as large as $100 \mathrm{~km}$ or as small as $50 \mathrm{~km}$, but a thickness of $25 \mathrm{~km}$ is definitely too small and a thickness of $200 \mathrm{~km}$ too large. Thus, models of the type proposed by Morgan $^{7}$ or Keen and Tramontini" are not compatible with the data.
A thickness of $75 \mathrm{~km}$ also fits profile $c$ where the crust is about $10 \mathrm{Myr}$ older than it is near $a$ and $b$ (Fig. 4c). In the absence of nearby seismic refraction stations, we assumed that the crustal structures correspond to those given as a function of age by Goslin et al. ${ }^{18}$. In addition, the temperature structure may already be affected significantly by the conductive flow of heat through the fracture zone. Consequently, profile $c$ is not as significant as the others.

The lithospheric thickness of $75 \mathrm{~km}$ obtained here is identical to that obtained by Sclater and Francheteau ${ }^{2}$ on the basis of different types of data (heat flow and depth). This confirms that such a plate tectonics model is successful in accounting for the main physical characteristics of the evolution of a lithospheric plate in its first $40 \mathrm{Myr}$ or so. It atso considerably strengthens the choice of physical parameters. The thickness is actually an estimate for a plate $30-40 \mathrm{Myr}$ old. The tempera-

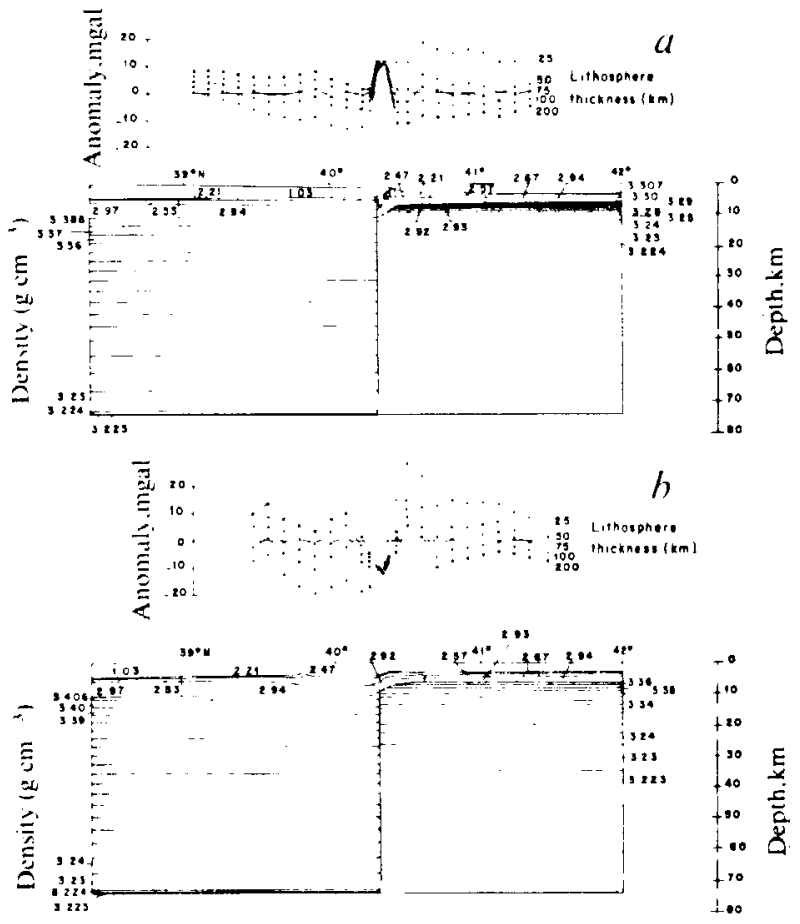

Fig. 3 Proposed density models across Mendocino Fracture Zone along profiles $a$ and $b$. The thickness of the lithosphere chosen for the models is $75 \mathrm{~km}$. The anomaly curves show the difference between observed and computed gravity anomalies for different lithosphere thicknesses. The density layers have been extended

to infinity at both ends to avoid artificial edge effects.

ture structure at the accreting plate boundary does not depend on the thickness of the plate; that is controlled by the vertical convection term and not by the conduction term. Thus, this model can be compared with that proposed by Parker and Oldenburg ${ }^{17}$ in which the thickness, $Z$, of the lithosphere changes with age roughly according to the formula:

$$
Z(t)=9.4 t^{\frac{1}{2}} \mathrm{~km}
$$

where $t$ is time in Myr.

Thus, $Z(30-40 \mathrm{Myr}) \sim 55 \mathrm{~km}$ and the estimate we obtain is in fair agreement with both models within the inherent uncertainties of the data and computations. We feel, however, that more systematic studies, with better seismic refraction and reflection control, across transform faults which juxtapose 

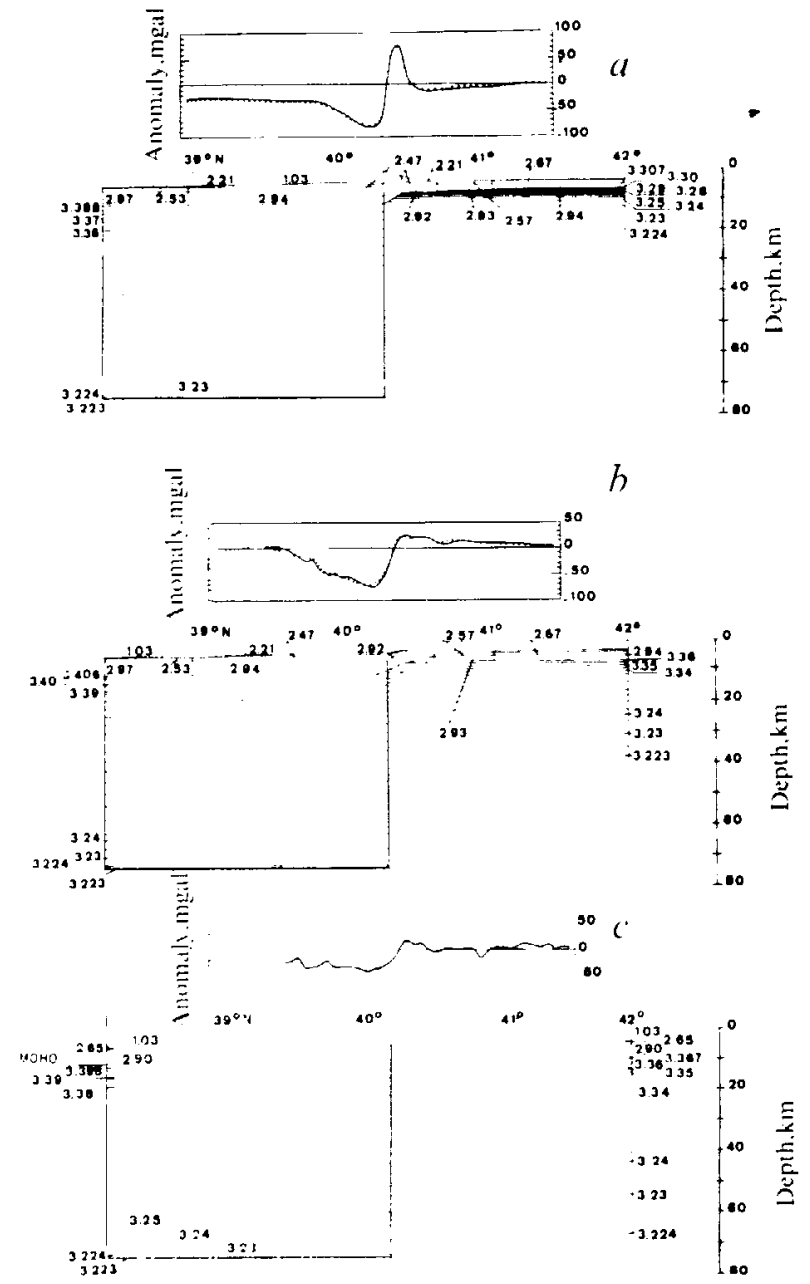

Fig. 4 Proposed density models across Mendocino Fracture Zone along profiles $a, b$ and $c$ and the corresponding observed Zone along profiles $a, b$ and $c$ and the corresponding observed
(solid lines) and computed (dotted lines) gravity anomalies. The thicknesses of the lithosphere chosen for the models is $75 \mathrm{~km}$. For $c$, the density model of the crust is a function of the age ${ }^{1 s}$ (see text).

lithospheric plates of different ages should provide much better constraints to models of lithospheric evolution.
We thank Jean Francheteau and Jason Morgan for discussion and advice.

\section{Jean-Claude Sibuet}

Xavier Le PichoN

Centre Océanologique de Bretagne, BP 337, 29273 Brest

Institut de Physique du Globe,

JEAN GOSLIN

9, quai Saint-Bernard, 75005 Paris, France

Received February 14, 1974.

1 Langseth, M. G., Le Pichon, X., and Ewing, M., J. geophys. Res., 71, 5321 (1966).

2 Sclater, J. G., and Francheteau, J., Geophys. J. R. asir. Soc., 20, $509(1970)$.

3 Le Pichon, X., Francheteau. J., and Bonnin, J., Plate Tectonics (Elsevier, Amsterdam, 1973).

4 Lambeck. K., Geophys. J. R. astr. Soc., 30, 37 (1972).

5 Talwani, M., Le Pichon, X., and Ewing. M., J. geophys. Res., 70, 341 (1965).

6 Le Pichon, X., Houtz, R. E., Drake, C. L., and Nafe, J. E., J. geophys. Res., 70, 319 (1965).

7 Morgan, W. J., J. geophys. Res., 70, 6189 (1965).

${ }^{8}$ Keen, C., and Tramontini, C., Geophys. J. R. astr. Soc., 20, 473 (1970).

9 Dehlinger, P., Couch, R. W., and Gemperle, M., J. geophys, Res., 72, 1233 (1967).

10 Dehlinger. P., Couch, R. W., McManus, D. A., and Gemperle, M. The Sea (edit by Maxwell, A. E.), 4, 133 (Wiley-Interscience, New York, 1970).

11 Atwater, T., and Menard, H. W., Earth planet. Sci. Le'tt., 7, 445 (1970).

12 Raitt, R. W., Abstr. Pap. int. Ass. phys. Oceanogr., 13th General Assembly, Berkeley, 6, 71 (1963).

13 Talwani, M., Sutton, G. H., and Worzel, J. L., J. geophys. Res., 64, 1545 (1959).

14 Hess, H. H., Nature, 203, 629 (1964).

15 Raitt, R. W., Shor, G. G., jun., Francis, T. J. G., and Morris, G. B., J. geophys, Res., 74, 3095 (1969).

16 Morris, G. B., Raitt, R. W., and Shor, G. G., J. geophys. Res., 74, 4300 (1969).

17 Parker, R. L., and Oldenburg, D. W., Nature, 242, 137 (1973).

18 Chase. T. E., Menard, H. W., and Mammerickx, J., Topographv of the North Pacific (Geologic Data Center, Scripps Institution of Oceanography and Institute of Marine Resources, La Jolla, 1971).

19 Gioslin, J., Beuzart, P., Francheteau, J., and Le Pichon, X., Mar. geophys. Res., 1, 418 (1972). 